solar observations which supplements that still being carried on at Greenwich. Work on the Reversible Transit Circle continues on a somewhat reduced scale, and the photometric observations are now sufficiently far advanced to make possible the construction of a framework of stars of magnitudes between 7 and 10 to which the magnitudes of the zone stars can be referred. With the 1940 batch of parallaxes the Observatory now enters the very restricted list of stations at which the distances of more than a thousand stars have been determined trigonometrically.

The section of the report which will be read with perhaps the greatest interest concerns the total solar eclipse of October 1, 1940. The main part of the programme was to measure the gravitational deflexion of light in the sun's field-the Einstein effect. The Greenwich expedition which was to have cooperated in this work was cancelled at the outbreak of war, and the entire programme was carried through, as planned, by the Cape staff. It is disappointing to have to record total failure in this part of the work. The field of stars close to the eclipsed sun was known beforehand to be a poor one; but eclipses are so few and far between that the attempt seemed justified. In fact, the lessened exposure time and reduced aperture necessary to prevent fogging of the plates by the rather bright sky, combined with the poor daytime 'seeing' on the Karroo to prevent any stars showing on the negatives at all. Astronomers all over the world will sympathize with H.M. Astronomer and his staff in this disappointment, particularly as observing conditions were otherwise good. Their sole compensation was in securing the only largescale photographs of the corona obtained during this eclipse-photographs which, though interesting and indeed important, represent a most inadequate reward for months of work.

\section{Prevention of Blindness}

IN its annual report for 1940 the United States National Society for the Prevention of Blindness stresses the increase in eye accidents brought about by extension of industrial production made necessary by national defence. Many firms are now using the industrial film known as "The Eyes Have It", which has been made available to the Society without cost by the Pullman Society. The Society is now planning an evaluation of vision-testing procedure used with school children and pre-school children in the hope of establishing a uniform procedure. During 1940 the National League for Nursing Education began a study of nursing education in sight conservation in co-operation with the Society. The Society has also arranged to co-operate with similar organizations in Latin America, has prepared an exhibition on glaucoma, and has continued its campaign to reduce blindness caused by venereal disease and fireworks.

\section{Earthquake in the Argentine}

The United States Coast and Geodetic Survey, in co-operation with Science Service and the Jesuit Seismological Association, has determined the pro- visional epicentre of the earthquake of July 3 at 7h. $11 \cdot 7 \mathrm{~m}$. U.T. as being at lat. $33^{\circ} \mathrm{S}$., long. $68^{\circ} \mathrm{W}$. The calculations have been based on reports from eleven seismograph stations. The epicentre is situated near the railway line about midway between Mendoza and San Luis. Activity in this region has been much less severe and more infrequent than between 1750 and 1910. There was a strong earthquake at Mendoza on May 22, 1782, though this was surpassed by the terrific shock in the same area which caused widespread destruction on March 20, 1861. Prior to this latter shock, San Luis was destroyed on April 9, 1849. Further intense shocks were experienced in both places up to about 1910 . It may be that, following the catastrophic shock of January 24, 1939, at Chillan in Chile (Nature, Feb. 11, 1939, p. 230), the centre of activity has moved eastwards. The earthquake of July 11, 1941, at 1 . $16^{\cdot 6 \mathrm{~m}}$. U.T. had its epicentre in the Pacific Ocean between the Galapagos Islands and the Isthmus of Panama.

\section{University of Cambridge}

UNDER the will of Mr. Alfred Corner, of Stavarton Road, Brondesbury Park, London, who died in 1934, the University has received $£ 1,440$ for the sole purposes of the Cambridge University Biochemical Laboratory. The full value of the bequest of which this is an instalment may approach $£ 1,800$.

The professorship of animal pathology will be vacated on December 31 by the resignation of Prof. T. Dalling.

\section{Announcements}

Sir Henry Dale, president of the Royal Society, has been awarded the Gold Medal for 1941 of the Royal Society of Medicine. The Medal is given triennially for "valuable contributions to the science and art of medicine".

The Right Hon. Lord Chatrield, recently Minister for the Co-ordination of Defence, has been elected president of the Institution of Naval Architects in succession to the late Lord Stonehaven.

Mr. R. A. WAtson WAtr, scientific adviser on telecommunications to the Air Ministry, has been elected president of the Association of Scientific Workers in succession to Prof. F. G. Donnan.

IN connexion with the fiftieth anniversary of the University of Chicago which was celebrated a short time ago, the sum of $9,200,000$ dollars has already been subscribed by the citizens of Chicago towards an anniversary fund of $12,000,000$ dollars. It is planned to raise the balance over a period of five years.

Dr. P. C. Koller and C. Auerbach, of the Institute of Animal Genetics, University of Edinburgh, writing with reference to their letter "Chromosome Breakage and Sterility in the Mouse" which appeared in NATURE of October 25, p. 501, wish to withdraw the last two sentences in the first paragraph of column 2 beginning with "We can confirm . . ." 